\title{
Maternal periconceptional consumption of sprouted potato and risks of neural tube defects and orofacial clefts
}

\author{
Wenli Ni ${ }^{1,2}$, Tian Tian ${ }^{1,2}$, Le Zhang ${ }^{1,2}$, Zhiwen $\mathrm{Li}^{1,2}$, Linlin Wang ${ }^{1,2^{*}}$ and Aiguo Ren ${ }^{1,2}$
}

\begin{abstract}
Background: The association between maternal consumption of sprouted potato during periconceptional period on the development of neural tube defects (NTDs) or orofacial clefts (OFCs) remains unclear. We aimed to examine the association between maternal consumption of sprouted potatoes during periconceptional period and risks of NTDs or OFCs.

Methods: Subjects included 622 NTD cases, 135 OFC cases and 858 nonmalformed controls, were recruited from a case-control study in Shanxi Province of northern China between 2002 and 2007. Information on demographics, maternal sprouted potato consumption, lifestyle behaviors and folic acid supplementation was collected.

Results: Consumption of sprouted potatoes was associated with elevated odds of total NTDs (OR=2.20; 95\% Cl, 1. 12-4.32) and anencephaly ( $\mathrm{OR}=2.48 ; 95 \% \mathrm{Cl}, 1.10-5.58)$; no association for spina bifida or encephalocele. Sprouted potato consumption increased the risk of total OFCs $(\mathrm{OR}=3.49 ; 95 \% \mathrm{Cl}, 1.29-9.49)$ and cleft lip with or without cleft palate $(C L \pm P)(O R=4.03 ; 95 \% C l, 1.44-11.28)$.

Conclusion: Maternal consumption of sprouted potatoes during periconceptional period may increase the risks of NTDs and OFCs. Given that potato is commonly consumed around the world, improper preservation and use should be a matter of concern in respect of the potential teratogenicity.
\end{abstract}

Keywords: Sprouted potato, Periconceptional period, Neural tube defects, Orofacial clefts

\section{Background}

Neural tube defects (NTDs) and orofacial clefts (OFCs) are relatively common congenital anomalies that have a significant impact on infant mortality, health, and quality of life [1-3]. NTDs result from failure of neural tube to close by the 28th day of postconception [4]. OFCs derive from an embryopathy with the tissues of the lip or palate not joining properly [5]. The etiologies of NTDs and OFCs are generally thought to be multifactorial, involving both genetic and environmental factors. Environmental factors such as maternal unhealthy diet, and exposure to smoking and alcohol consumption contribute to these congenital anomalies [6-10]. Nutrient

\footnotetext{
* Correspondence: linlinwang@bjmu.edu.cn

'Peking University Institute of Reproductive and Child Health, National Health Commission Key Laboratory of Reproductive Health, Beijing 100191, China

${ }^{2}$ Department of Epidemiology and Biostatistics, School of Public Health, Peking University Health Science Center, Beijing 100191, China
}

deficiency as a part of harmful dietary factors, especially folic acid deficiency, has been shown to be associated with increased risks of NTDs and OFCs [11-13]. Toxins in food are another important part of harmful dietary factors, however, the role of toxins in the occurrence of these two birth defects remains largely unknown.

Toxins in staple food have a great influence on human health because of the large amount of consumption. Today potato, as the 4th major food crop after rice, wheat and maize, is cultivated worldwide under various climatic conditions, and is consumed commonly throughout the world $[14,15]$. However, in the process of storage and transportation, potato is easy to become green and spout in inappropriate environment [16, 17]. Sprouted potato contains high concentration of solanine that is a toxic glycoalkaloid [18]. The reproductive toxicity of solanine has been assessed in vitro or in vivo animal studies [15, 19-23]. Steroidal glycoalkaloid from

(C) The Author(s). 2018 Open Access This article is distributed under the terms of the Creative Commons Attribution 4.0 International License (http://creativecommons.org/licenses/by/4.0/), which permits unrestricted use, distribution, and 
potatoes could inhibit pre-implantation embryo development when exposing to oocytes and fertilized ova in vitro [15]. Additionally, solanine was found to have teratogenicity, such as inducing NTDs, OFCs, microcephaly, and severe muscular kinking in frog embryo, mice, or hamster [19-23]. However, only one study with a small sample size reported that sprouted potato consumption might be a risk factor for NTDs [24], while no study investigated the effect of maternal consumption of sprouted potato during periconceptional period on the development of OFCs in humans.

In the present study, we aimed to examine the association between maternal periconceptional consumption of sprouted potatoes and risks for NTDs and OFCs.

\section{Methods}

\section{Study design}

The data were from a case-control study of birth defects in four counties (Pingding, Xiyang, Taigu and Zezhou) of Shanxi province in northern China, which has been described elsewhere [25]. Concisely, a population-based surveillance system of birth defects was established in the study area in 2002. The surveillance system monitored major external structural birth defects through active case ascertainment. Cases with major external structural malformations were ascertained from live births, stillbirths, and elective terminations. County or township health workers verified the diagnoses by physical examination of the fetal body for all pregnancy outcomes and filled out a reporting form for each case. When a case infant was identified, a newborn control without any external structural birth defect was matched to the case infant by county, sex, maternal ethnic group, and date of the last menstrual period ( \pm 4 months). The study was approved by the Institutional Review Board of Peking University Health Science Centre. All participants provided written informed consent.

\section{Data collection}

Trained local health care workers conducted face-to-face interviews with mothers of cases and controls within 1 week of delivery or termination of pregnancies to collect the exposure information using a structured questionnaire. Data were collected on the mother's demographic characteristics, reproductive history, lifestyle, folic acid supplementation, smoking exposure (active or passive), and consumption of sprouted potato and other foods from 1 month before through 2 months after conception. Definition of maternal sprouted potato consumption is eating the sprouts of potato or any skin that started to turn green. Definition of passive smoking is staying in the tobacco smoking environmental for at least $30 \mathrm{~min}$ and at least 1 time per week. Definition of higher consumption of $B$ vitamins is that maternal consumption of fresh vegetables and fresh fruit at $\geq 4$ meals/week or maternal periconceptional use of folic acid, otherwise, it was lower consumption of B vitamins. Consumption of sprouted potato was classified as $<1 \mathrm{meal} /$ week, $1-3$ meals/week, 4-6 meals/week, or $>6$ meals/week; we combined two frequency categories (" $4-6$ meals/week" and "> 6 meals/week") into a single group (referred to as " $\geq 4$ meals/week"), because subjects with the highest consumption of sprouted potato frequency of " $>6$ meals/week" were few.

\section{Study population}

For this study, we used data collected from June 2002 through December 2007. The cases included newborns with NTDs or OFCs assigned an ICD-9 code of 740.0 (anencephaly), 741.0 (spina bifida), 742.0 (encephalocele), 749.0 (cleft palate), 749.1 (cleft lip), or 749.2 (cleft lip with cleft palate). A total of 1615 participants were available for analyses, including 622 NTD cases (281 with anencephaly, 293 with spina bifida, and 48 with encephalocele), 135 OFC cases (126 with cleft lip with or without cleft palate, 9 with cleft palate only), and 858 controls. Because OFCs and NTDs are rare diseases and few studies investigated the assocaition between sprouted potato consumption and birth defects, no information about the proportion of maternal sprouted potato exposure in control group or OR value can be referred for calculating sample size. In the present study, we used an empirical sample size. The statistical powers were $96.4 \%$ for NTDs and $99.7 \%$ for OFCs of this given the sample size (622 NTD cases, 135 OFC cases, and 858 controls) by PASS.11 software calculation, which were adequate to test the existence of significantly association between the sprouted potato consumption and NTDs and OFCs in this study.

\section{Statistical analyses}

The original study used a pair-matching design, but for some data about sprouted potato consumption were not available for evaluation, the matching was broken in this analysis. The differences in demographic and lifestyle characteristics between the case and control group were evaluated by Chi-square test or Fisher's exact test. Risk was estimated by the use of OR, and the precision of each OR was assessed by its 95\% CI. We used the unconditional logistic regression and Chi-square trend test to evaluate the associations between sprouted potato consumption and risks of NTDs and OFCs, respectively. We calculated two adjusted OR (aOR) with different logistic models. The $\mathrm{aOR}_{1}$ was adjusted only for demographic and obstetrics variables, including maternal age, BMI, education, occupation, parity, history of pregnancy affected by birth defects, infant sex, folic acid supplementation, season of conception, alcohol drinking, and 
maternal smoking exposure. Considering the other dietary characteristics which may generate confounding bias, we also estimated $\mathrm{aOR}_{2}$ by additionally adjusting for consumption of meat or fish, consumption of egg or milk, consumption of fresh vegetable, consumption of fresh fruit, and consumption of legumes. Another, the associations between sprouted potato consumption and risks of NTDs and OFCs among mother with higher consumption of $\mathrm{B}$ vitamins consumption versus mother with lower consumption of B vitamins were conducted. We considered $p<0.05$ statistically significant. All data were analyzed using SPSS 23.0 software (SPSS, Chicago, IL, USA).

\section{Results}

\section{Characteristics of study population}

The demographic and lifestyle characteristics of study participants are summarized in Table 1. More than 99\% mothers were of Han ethnicity. Compared with control mothers, mothers of infants with NTDs were more likely to have a lower BMI and a lower education level, to be multiparous, to report a history of pregnancy affected by birth defects, to have alcohol drinking exposure, and to have smoking exposure; mothers of infants with OFCs were more likely to be not farmers, to have a lower education level, and to have a male infant.

Additional file 1: Table S1 shows the dietary characteristics of study participants. Compared to control mothers, mothers of infants with NTDs were more likely to have lower frequencies of meat or fish consumption, egg or milk consumption, fresh vegetables consumption, fresh fruit consumption, and beans or bean products consumption. There was no significant difference between OFC cases and controls with respect to dietary characteristics.

Table 2 shows the association between sprouted potato consumption and risks of total NTDs and subtypes of NTDs. When maternal consumption of sprouted potato at $<1 \mathrm{meal} /$ week was used as the reference, increases in the risks for total NTDs of 2.20-fold (95\% CI, 1.12-4.32) were observed for maternal consumption at $\geq 4$ meals/ week, respectively. The positive relationship was also present for anencephaly but not for spina bifida or encephalocele; the adjusted ORs for anencephaly in association with maternal consumption of sprouted potato at $\geq 4$ meals/week were 2.48 (95\% CI, 1.10-5.58). Trend analysis showed a clear positive dose-response relationship between risks for NTD or anencephaly and sprouted potato consumption $(P$ for trend $<0.05)$.

Table 3 details the association between sprouted potato consumption and risks of total OFCs and $\mathrm{CL} \pm \mathrm{P}$. When maternal consumption of sprouted potato at $<1$ $\mathrm{meal} /$ week was used as the reference, increases in the risks for total OFCs and $\mathrm{CL} \pm \mathrm{P}$ of 3.49 -fold (95\% CI,
1.29-9.49) and 4.03-fold (95\% CI, 1.44-11.28) were observed for maternal consumption at $\geq 4$ meals/week, respectively.

We also assessed association between maternal sprouted potato consumption and risks of NTDs and OFCs in stratified by consumption of B vitamin (Additional file 1: Table S2 and S3).

Among mother with lower consumption of B vitamins, maternal consumption of sprouted potato at $\geq 4$ meals/ week, still were significantly associated with NTDs and OFCs, the aOR were $1.84(1.02-7.86)$ for total NTD, $3.21(1.00-10.35)$ for anencephaly, $12.17(2.22-66.63)$ for total OFCs, and 15.65(2.68-91.40) for $\mathrm{CL} \pm \mathrm{P}$. However, no significant associations were observed between maternal consumption of sprouted potato and NTDs and OFCs among mother with a higher consumption of $\mathrm{B}$ vitamins. Recall bias is the main concern in case-control studies. The women who have infant with birth defects might over-report unhealthy exposure. To assess whether such a recall bias existed in the present study, we further analyzed the distribution of consumption of sprouted potato during periconceptional period between women had infant with limb malformations (polydactylism, syndactylia, limb shortening, strephenopodia, or strephexopodia) without other malformations and controls (Additional file 1: Table S4). No difference was found in the distribution of sprouted potato consumption between cases and controls $(P=0.066)$.

\section{Sensitivity analysis}

To test the robustness of our results, we conducted a sensitivity analysis limited to the subjects without a history of pregnancy affected by birth defects. The results did not change after removing 65 subjects with a history of pregnancy affected by birth defects (Additional file 1: Tables S5 and S6).

\section{Discussion}

In this population-based case-control study, we examined potential association between maternal consumption of sprouted potatoes during periconceptional period and risks for NTDs and OFCs. Overall, we observed that maternal consumption of sprouted potatoes increased the risk for total NTDs, anencephaly, total OFCs, and $\mathrm{CL} \pm \mathrm{P}$.

Few literatures reported the association between sprouted potato consumption and risk of NTDs in humans [24]. In our study, based on relatively large sample of NTD cases $(n=622)$ versus controls $(n=858)$, we found about 2.20-fold increased risks for NTDs among mothers who consumed sprouted potato at $\geq 4$ meals/ week and the risk increased with the rising consumption frequency of sprouted potato. One study reported that sprouted potato consumption was a risk factor affecting 
Table 1 Characteristics of women who had pregnancies affected by NTDs or OFCs (cases) and women who delivered healthy infants (controls)

\begin{tabular}{|c|c|c|c|c|c|}
\hline \multirow[t]{3}{*}{ Characteristics } & \multirow{3}{*}{$\begin{array}{l}\text { Controls } \\
(n=858) \\
\\
\mathrm{n}(\%)^{\mathrm{a}}\end{array}$} & \multicolumn{4}{|l|}{ Cases } \\
\hline & & \multicolumn{2}{|l|}{$\begin{array}{l}\text { NTDs } \\
(n=622)\end{array}$} & \multicolumn{2}{|l|}{$\begin{array}{l}\text { OFCs } \\
(n=135)\end{array}$} \\
\hline & & $\mathrm{n}(\%)^{a}$ & $p$-Value & $\overline{n(\%)^{a}}$ & $p$-Value \\
\hline \multicolumn{6}{|l|}{ Maternal age (years) } \\
\hline$<25$ & $358(42.4)$ & 249(40.8) & 0.800 & $61(47.3)$ & 0.140 \\
\hline $25-29$ & $268(31.7)$ & $196(32.0)$ & & $45(34.9)$ & \\
\hline$\geq 30$ & $219(25.9)$ & $166(27.2)$ & & $23(17.8)$ & \\
\hline \multicolumn{6}{|l|}{ BMI $\left(\mathrm{kg} / \mathrm{m}^{2}\right)$} \\
\hline$<18.5$ & $53(6.3)$ & $45(7.5)$ & 0.002 & $11(8.5)$ & 0.339 \\
\hline $18.5-23.9$ & $417(49.8)$ & $350(58.0)$ & & $70(53.8)$ & \\
\hline$\geq 24$ & $368(43.9)$ & $208(34.5)$ & & $49(37.7)$ & \\
\hline \multicolumn{6}{|l|}{ Ethnicity } \\
\hline Han & $853(99.6)$ & $620(99.8)$ & 1.000 & $135(100)$ & 1.000 \\
\hline Other & $3(0.4)$ & $1(0.2)$ & & $0(0)$ & \\
\hline \multicolumn{6}{|l|}{ Occupation } \\
\hline Farmer & $568(66.9)$ & $420(69.2)$ & 0.356 & $73(54.1)$ & 0.004 \\
\hline Other & $281(33.1)$ & $187(30.8)$ & & $62(45.9)$ & \\
\hline \multicolumn{6}{|l|}{ Education } \\
\hline Primary or lower & $51(6.0)$ & $101(16.3)$ & $<0.001$ & $18(13.5)$ & 0.002 \\
\hline Junior high & $656(76.9)$ & $445(71.8)$ & & $87(65.4)$ & \\
\hline High school or above & $146(17.1)$ & $74(11.9)$ & & $28(21.1)$ & \\
\hline \multicolumn{6}{|l|}{ Parity } \\
\hline Primiparas & $538(62.8)$ & $345(56.4)$ & 0.013 & $95(70.9)$ & 0.069 \\
\hline Multiparas & $319(37.2)$ & $267(43.6)$ & & $39(29.1)$ & \\
\hline \multicolumn{6}{|c|}{ History of pregnancy affected by birth defects } \\
\hline Yes & $18(2.1)$ & $42(6.8)$ & $<0.001$ & $5(3.7)$ & 0.360 \\
\hline No & $838(97.9)$ & $573(93.2)$ & & $130(96.3)$ & \\
\hline \multicolumn{6}{|l|}{ Infant sex } \\
\hline Male & $404(47.6)$ & $268(43.9)$ & 0.153 & $84(62.2)$ & 0.002 \\
\hline Female & $444(52.4)$ & $343(56.1)$ & & $51(37.8)$ & \\
\hline \multicolumn{6}{|l|}{ Folic acid supplementation } \\
\hline Yes & $113(13.7)$ & $65(10.7)$ & 0.090 & $20(14.4)$ & 0.690 \\
\hline No & $709(86.3)$ & $540(89.3)$ & & $113(85.6)$ & \\
\hline \multicolumn{6}{|c|}{ Maternal smoking exposure } \\
\hline Yes & $491(57.6)$ & $423(68.6)$ & $<0.001$ & $84(62.2)$ & 0.315 \\
\hline No & $361(42.4)$ & $194(31.4)$ & & $51(37.8)$ & \\
\hline \multicolumn{6}{|l|}{ Alcohol drinking } \\
\hline Yes & $5(0.6)$ & $9(1.4)$ & 0.107 & $4(3.0)$ & 0.024 \\
\hline No & $848(99.4)$ & $613(98.4)$ & & $131(13.4)$ & \\
\hline \multicolumn{6}{|l|}{ Season of conception } \\
\hline Spring & $202(24.1)$ & $156(25.4)$ & 0.657 & $36(26.9)$ & 0.857 \\
\hline Summer & $206(24.6)$ & $142(23.2)$ & & $29(21.6)$ & \\
\hline Autumn & $207(24.7)$ & $164(26.8)$ & & $33(24.6)$ & \\
\hline Winter & $222(26.5)$ & $151(24.6)$ & & $36(26.9)$ & \\
\hline
\end{tabular}


Table 2 Sprouted potato consumption and risks of total NTDs and NTD subtypes

\begin{tabular}{|c|c|c|c|c|c|c|c|c|c|}
\hline \multirow[t]{2}{*}{$\begin{array}{l}\text { Sprouted potato } \\
\text { consumption }\end{array}$} & \multirow{2}{*}{$\begin{array}{l}\text { Controls } \\
(n=858) \\
\mathrm{n}(\%)\end{array}$} & \multicolumn{2}{|l|}{$\begin{array}{l}\text { Total NTDs } \\
(n=622)\end{array}$} & \multicolumn{2}{|c|}{$\begin{array}{l}\text { Anencephaly } \\
(n=281)\end{array}$} & \multicolumn{2}{|c|}{$\begin{array}{l}\text { Spina bifida } \\
(n=293)\end{array}$} & \multicolumn{2}{|c|}{$\begin{array}{l}\text { Encephalocele } \\
(n=48)\end{array}$} \\
\hline & & $n(\%)$ & OR $(95 \%$ Cl) & $n(\%)$ & OR $(95 \% \mathrm{Cl})$ & $n(\%)$ & OR $(95 \% \mathrm{Cl})$ & $\mathrm{n}(\%)$ & OR $(95 \% \mathrm{Cl})$ \\
\hline \multicolumn{10}{|l|}{ Crude OR } \\
\hline$<1$ meal/week & 737 (85.9) & $512(82.1)$ & 1.00 & 229 (81.5) & 1.00 & $243(83.0)$ & 1.00 & $38(79.2)$ & 1.00 \\
\hline 1-3 meals/week & 99 (11.5) & 79 (12.7) & $1.15(0.84-1.58)$ & $34(12.1)$ & $1.11(0.73-1.68)$ & 37 (12.6) & $1.13(0.75-1.69)$ & $8(16.7)$ & $1.57(0.71-3.46)$ \\
\hline$\geq 4$ meals/week & $22(2.6)$ & $33(5.3)$ & $2.16(1.24-3.75)$ & $18(6.4)$ & $2.63(1.39-5.00)$ & $13(4.4)$ & $1.79(0.89-3.60)$ & $2(4.2)$ & $1.76(0.75-1.69)$ \\
\hline \multicolumn{10}{|l|}{ Adjusted $\mathrm{OR}_{1}{ }^{a}$} \\
\hline$<1$ meal/week & 737 (85.9) & $512(82.1)$ & 1.00 & 229 (81.5) & 1.00 & $243(83.0)$ & 1.00 & 38 (79.2) & 1.00 \\
\hline 1-3 meals/week & 99 (11.5) & 79 (12.7) & $1.28(0.88-1.87)$ & $34(12.1)$ & $1.22(0.74-2.02)$ & 37 (12.6) & $1.23(0.77-1.97)$ & $8(16.7)$ & $2.13(0.86-5.27)$ \\
\hline$\geq 4$ meals/week & $22(2.6)$ & $33(5.3)$ & $2.22(1.18-4.18)$ & $18(6.4)$ & $2.42(1.15-5.11)$ & $13(4.4)$ & $2.03(0.94-4.39)$ & $2(4.2)$ & $2.22(0.46-10.79)$ \\
\hline \multicolumn{10}{|l|}{ Adjusted $\mathrm{OR}_{2}{ }^{\mathrm{b}}$} \\
\hline$<1$ meal/week & 737 (85.9) & $512(82.1)$ & 1.00 & 229 (81.5) & 1.00 & $243(83.0)$ & 1.00 & 38 (79.2) & 1.00 \\
\hline 1-3 meals/week & 99 (11.5) & 79 (12.7) & $1.11(0.75-1.63)$ & $34(12.1)$ & $1.06(0.63-1.78)$ & 37 (12.6) & $1.23(0.76-2.00)$ & $8(16.7)$ & $1.82(0.70-4.73)$ \\
\hline$\geq 4$ meals/week & $22(2.6)$ & $33(5.3)$ & $2.20(1.12-4.32)$ & $18(6.4)$ & $2.48(1.10-5.58)$ & $13(4.4)$ & $2.17(0.97-4.85)$ & $2(4.2)$ & $3.18(0.61-16.65)$ \\
\hline$P$ for trend & & 0.009 & & 0.011 & & 0.117 & & 0.203 & \\
\hline
\end{tabular}

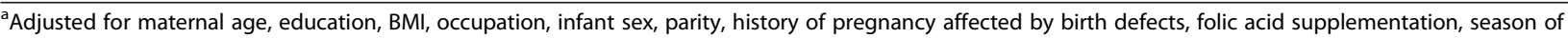
conception, alcohol drinking, and maternal smoking exposure

${ }^{b}$ Adjusted for maternal age, education, BMl, occupation, infant sex, parity, history of pregnancy affected by birth defects, folic acid supplementation, season of conception, alcohol drinking, maternal smoking exposure, consumption of meat or fish, consumption of egg or milk, consumption of fresh vegetable,

consumption of fresh fruit, and consumption of legumes

the occurrence of NTDs in mothers with NTD fetuses $(n=99)$ and control mothers $(n=99)$ [24]. NTD subtype analysis was absent in the previous study due to the small sample size. To our knowledge, our study is the first to examine the association between maternal sprouted potato consumption during periconceptional period and risks for NTD subtypes. We found a 2.48-fold increased risk for anencephaly not for other NTD subtypes among mothers who consumed sprouted potato at $\geq 4$ meals/week. Several previous animal studies support our findings. Water suspensions of sprouts from seven potato varieties, gavaged at concentration of 2.5$3.5 \mathrm{~g} / \mathrm{kg}$ on days $8-15$ of gestation, produced NTD abnormalities in one strain of hamsters [22]. Oral administration of solanines at $0.44 \mathrm{mmol} / \mathrm{kg}$ dose on days $8-15$ of gestation could induce NTDs in Syrian hamsters [23]. Glycoalkaloids were also found to induce anencephaly, microcephaly, and severe muscular kinking at a dosage of $4-5 \mathrm{mg} / \mathrm{L}$ in frog embryo $[19,20]$.

No previous studies have examined the role of maternal consumption of sprouted potatoes during periconceptional period in OFCs in humans. In our study, we found a 3.49-fold elevated risk for OFCs among mothers who consumed sprouted potato at $\geq 4$ meals/week. In animal experiment, potato sprouts has been shown to be teratogenic for OFCs. Hamsters gavaged sprouts of potato suspended in water at about $2.2 \pm 0.3 \mathrm{~g} / \mathrm{kg}$ dose on days $8-15$ of gestation presented OFC phenotypes [21].

B vitamin consumption (folic acid supplementation) has been shown a beneficial factor against the occurrence of NTDs and OFCs [26, 27]. We, therefore, examined the association between maternal sprouted potato consumption and risks of NTDs and OFCs in stratified by consumption of B vitamin. Among mother with lower consumption of B vitamins, we still found maternal consumption of sprouted potatoes significantly associated with NTDs and OFCs, however, no significant associations were observed among mother with a higher consumption of $B$ vitamins, which meaning that $B$ vitamins maybe antagonize the toxicity of solanine. Previous study also showed that folic acid could decrease glycoalkaloids-induced polarization, and then decrease glycoalkaloid toxicity [19].

Potato is an important food crop and constitutes an integral part of diets in many countries around the world, including China [28]. During the storage process, potato is easy to sprout in inappropriate environment and produce a large amount of solanine, which can be increased to $500 \mathrm{mg} / 100 \mathrm{~g}$ and is far more than the safety standard $(20 \mathrm{mg} / 100 \mathrm{~g})$ [29]. Solanine is stable during cooking even in frying oil at $180^{\circ} \mathrm{C}$ [19]. Home processing methods (boiling, cooking, frying, and microwaving) have small and variable effects on solanine [30, 31]. Therefore, most of solanines (potato glycoalkaloids) are taken into the bodies when pregnant women have sprouted or green potatoes. The mechanisms underlying the teratogenicity of solanines are little investigated. It has been suggested that potato glycoalkaloids interfere with transport across cell membranes of $\mathrm{Ca}^{2+}$ and $\mathrm{Na}^{+}$ ions [32-35]. The potential teratogenicity of sprouted 
Table 3 Sprouted potato consumption and risks of total OFCs and OFC subtypes

\begin{tabular}{|c|c|c|c|c|c|}
\hline \multirow[t]{2}{*}{$\begin{array}{l}\text { Sprouted potato } \\
\text { consumption }\end{array}$} & \multirow{2}{*}{$\begin{array}{l}\text { Controls } \\
(n=858) \\
\mathrm{n}(\%)\end{array}$} & \multicolumn{2}{|l|}{$\begin{array}{l}\text { Total OFCs } \\
(n=135)\end{array}$} & \multicolumn{2}{|l|}{$\begin{array}{l}C L \pm P \\
(n=126)\end{array}$} \\
\hline & & $n(\%)$ & $\mathrm{OR}(95 \% \mathrm{Cl})$ & $n(\%)$ & OR(95\% Cl) \\
\hline \multicolumn{6}{|l|}{ Crude OR } \\
\hline$<1$ meal/week & 737 (85.9) & $111(82.2)$ & 1.00 & $104(82.5)$ & 1.00 \\
\hline 1-3 meals/week & 99 (11.5) & $16(11.9)$ & $1.07(0.61-1.89)$ & $14(11.1)$ & $1.00(0.55-1.82)$ \\
\hline$\geq 4$ meals/week & $22(2.6)$ & $8(5.9)$ & $2.41(1.05-5.56)$ & $8(6.3)$ & $2.58(1.12-5.94)$ \\
\hline \multicolumn{6}{|l|}{ Adjusted $\mathrm{OR}_{1}{ }^{a}$} \\
\hline$<1$ meal/week & 737 (85.9) & $111(82.2)$ & 1.00 & $104(82.5)$ & 1.00 \\
\hline 1-3 meals/week & 99 (11.5) & $16(11.9)$ & $1.37(0.70-2.69)$ & $14(11.1)$ & $1.34(0.67-2.68)$ \\
\hline$\geq 4$ meals/week & $22(2.6)$ & $8(5.9)$ & $2.99(1.12-8.03)$ & $8(6.3)$ & $3.17(1.18-8.55)$ \\
\hline \multicolumn{6}{|l|}{ Adjusted $\mathrm{OR}_{2}{ }^{\mathrm{b}}$} \\
\hline$<1$ meal/week & 737 (85.9) & $111(82.2)$ & 1.00 & $104(82.5)$ & 1.00 \\
\hline 1-3 meals/week & 99 (11.5) & 16 (11.9) & $1.10(0.55-2.21)$ & $14(11.1)$ & $1.20(0.57-2.50)$ \\
\hline$\geq 4$ meals/week & $22(2.6)$ & $8(5.9)$ & $3.49(1.29-9.49)$ & $8(6.3)$ & $4.03(1.44-11.28)$ \\
\hline$P$ for trend & & 0.094 & & 0.099 & \\
\hline
\end{tabular}

${ }^{a}$ Adjusted for maternal age, maternal education, BMI, occupation, infant sex, parity, history of pregnancy affected by birth defects, folic acid supplementation, season of conception, alcohol drinking, and maternal smoking exposure

${ }^{\mathrm{b}}$ Adjusted for maternal age, maternal education, BMl, occupation, infant sex, parity, history of pregnancy affected by birth defects, folic acid supplementation, season of conception, alcohol drinking, maternal smoking exposure, consumption of meat or fish, consumption of egg or milk, consumption of fresh vegetable, consumption of fresh fruit, and consumption of legumes

potatoes may be involved in solanine direct or indirect adverse effects on transport across cell membranes [19].

There is strength in our study. It was a relatively large population-based study with collection of the information on sprouted potato consumption and other key confounding factors, which enables us to investigate the relationship between sprouted potato consumption and NTDs with adjustment of potential interference factors. However, our study has several limitations. An intrinsic limitation of the case-control study is recall bias. Case mothers may over-report factors they believe to be risk factors of birth defects in comparison with control mothers. For assessment of recall bias, we determined whether a difference existed in the distribution of maternal consumption of sprouted potatoes during periconceptional period between women have infant with and without limb malformations. The result showed that the distribution of sprouted potato consumption between limb malformation cases and controls is similar, suggesting that recall bias of over-report was small in this study. On the other hand, to further minimize the recall bias, participants were interviewed within the first week after delivery or pregnancy termination, and the researchers helped women to confirm the period of exposure according to the dates of their last menstrual period. Second, the sample size for some subgroups was small, which limited our ability to detect statistical differences. Third, the exposure information in this study was obtained from a questionnaire. We did not measure the solanine quantity in sprouted potato. So, we can not provide data on the amount of solanine contained in a sprouted potato and the amount of solanine consumed per meal. Finally, information about consumption of dietary we collected does not specify the frequency of certain food items consumption or the weight of food consumption, and just were roughly classified by consumption of meat or fish, egg or milk, fresh vegetable, fresh fruit, and legumes in present study. So we did not use a nutrient based adjustment procedures in this study.

\section{Conclusions}

In conclusion, maternal consumption of sprouted potatoes during periconceptional period may increase the risks for NTDs and OFCs. Our study is the first to examine the association between maternal periconceptional sprouted potato consumption and risks of NTD subtypes and OFCs in human. Our findings provide novel insight into the etiology of NTDs and OFCs and propose a new way to prevent from birth defects. Potato is a commonly consumed food items in the world, and improper preservation and use should be a matter of concern. The dietary guidance for pregnant women should be emphasized and the knowledge level of healthy fertility in reproductive woman should be improved. Maternal consumption of sprouted potato could be avoided through health education and pre-pregnancy care. Further studies aiming to replicate the findings in other racial groups and to construe the fundamental mechanism underlying the association of sprouted potato consumption and birth defects are needed. 


\section{Additional file}

Additional file 1: Table S1. Dietary characteristics of women who had pregnancies affected by NTDs or OFCs (cases) and women who delivered healthy infants (controls). Table S2. Sprouted potato consumption and risks of total NTDs and NTD subtypes stratified by consumption of B vitamin. Table S3. Sprouted potato consumption and risks of total OFCs and OFC subtypes stratified by consumption of B vitamin. Table S4. The distribution of sprouted potato consumption between Limb malformation cases and controls. Table S5. Sensitivity analysis: Sprouted potato consumption and risks of total NTDs and NTD subtypes. Table S6. Sensitivity analysis: Sprouted potato consumption and risks of total OFCs and OFC subtypes. (DOCX $34 \mathrm{~kb}$ )

\section{Abbreviations}

BMI: Body mass index; Cl: Confidences interval; $\mathrm{CL} \pm \mathrm{P}$ : Cleft lip with or without cleft palate; NTDs: Neural tube defects; OFCs: Orofacial clefts; OR: Odds radio

\section{Acknowledgments}

We are grateful to the local healthcare workers in four counties (Pingding, Xiyang, Taigu and Zezhou) of Shanxi Province, China, for their assistance with data collection during the course of the study. We also thank the study participants for their contributions.

\section{Funding}

Supported by the National Natural Science Foundation of China (Grant No.

81472987 and 81773441); Beijing Natural Science Foundation (Grant No.

7162094); and the National Key Research and Development Program,

Ministry of Science and Technology, P.R. China (Grant No. 2016YFC1000501).

\section{Availability of data and materials}

The dataset of the current study is available from the corresponding author upon reasonable request.

\section{Authors' contributions}

LW conceived and designed the study; WN and LW posed the hypothesis, analyzed the data, and drafted the manuscript; AR and ZL established the population-based surveillance system; $T T$ and $L Z$ contributed to acquisition and cleaning of data; $L W, Z L$ and AR contributed to reviewing the manuscript. All authors read and approved the final manuscript.

\section{Ethics approval and consent to participate}

The study was approved by the Institutional Review Board of Peking University Health Science Centre. All participants provided written informed consent.

\section{Consent for publication}

Not applicable.

\section{Competing interests}

The authors declare that they have no competing interests.

\section{Publisher's Note}

Springer Nature remains neutral with regard to jurisdictional claims in published maps and institutional affiliations.

Received: 21 July 2018 Accepted: 13 November 2018 Published online: 28 November 2018

\section{References}

1. Lockhart E. The mental health needs of children and adolescents with cleft lip and/or palate. Clin Child Psychol Psychiatry. 2003;8:7-16.

2. Hunt $O$, Burden D, Hepper P, Johnston C. The psychosocial effects of cleft lip and palate: a systematic review. Eur J Orthod. 2005:27:274

3. Detrait ER, George TM, Etchevers HC, Gilbert JR, Vekemans M, Speer MC. Human neural tube defects: developmental biology, epidemiology, and genetics. Neurotoxicol Teratol. 2005;27:515-24.
4. Wilde JJ, Petersen JR, Niswander L. Genetic, epigenetic, and environmental contributions to neural tube closure. Annu Rev Genet. 2014:48:583-611.

5. Mossey PA, Little J, Munger RG, Dixon MJ, Shaw WC. Cleft lip and palate. Lancet. 2009:374:1773-85.

6. Shaw GM, Carmichael SL, Laurent C, Rasmussen SA. Maternal nutrient intakes and risk of orofacial clefts. Epidemiology. 2006;17:285-91.

7. Kirke PN, Daly LE, Elwood JH. A randomized trial of low-dose folic-acid to prevent neural-tube defects. Arch Dis Child. 1992;67:1442-6.

8. Grewal J, Carmichael SL, Ma C, Lammer EJ, Shaw GM. Maternal periconceptional smoking and alcohol consumption and risk for select congenital anomalies. Birth Defects Res A Clin Mol Teratol. 2008;82:519-26.

9. Krapels IP, van Rooij IA, Ocke MC, West CE, van der Horst CM, SteegersTheunissen RP. Maternal nutritional status and the risk for orofacial cleft offspring in humans. J Nutr. 2004;134:3106-13.

10. Sotresalvarez D, Siegariz AM, Herring AH, Carmichael SL, Feldkamp ML, Hobbs CA, Olshan AF. Maternal dietary patterns are associated with risk of neural tube and congenital heart defects. Am J Epidemiol. 2013;177:1279.

11. Berry RJ, Li Z, Erickson JD, Li S, Moore CA, Wang H, Mulinare J, Zhao P, Wong LYC, Gindler J. Correction: Prevention of neural-tube defects with folic acid in China. N Engl J Med. 1999;341:1864.

12. Figueiredo RF, Figueiredo N, Feguri A, Bieski I, Mello R, Espinosa M, Damazo AS. The role of the folic acid to the prevention of orofacial cleft: an epidemiological study. Oral Dis. 2015;21:240-7.

13. Johansen AM, Lie RT, Wilcox AJ, Andersen LF, Drevon CA. Maternal dietary intake of vitamin a and risk of orofacial clefts: a population-based casecontrol study in Norway. Am J Epidemiol. 2008;167:1164-70.

14. Paul V, Ezekiel R, Pandey R. Sprout suppression on potato: need to look beyond CIPC for more effective and safer alternatives. J Food Sci Technol. 2016:53:1-18.

15. Wang S, Panter KE, Gaffield W, Evans RC, Bunch TD. Effects of steroidal glycoalkaloids from potatoes (Solanum tuberosum) on in vitro bovine embryo development. Anim Reprod Sci. 2005;85:243-50

16. Friedman M, Mcdonald GM. Glycoalkaloids in fresh and processed potatoes. Acs Symposium. 1996;631:189-205

17. Hopkins J. The glycoalkaloids: naturally of interest (but a hot potato?). Food Chem Toxicol. 1995;33:323-8.

18. Barceloux D. Potatoes, tomatoes, and solanine toxicity (Solanum tuberosum L., Solanum lycopersicum L.). Dis Mon. 2009;55:391-402.

19. Friedman M. Potato glycoalkaloids and metabolites: roles in the plant and in the diet. J Agric Food Chem. 2006;54:8655-81.

20. Friedman M, Rayburn JR, Bantle JA. Structural relationships and development toxicity of Solanum alkaloids in the frog embryo teratogenesis assay-Xenopus. J Agric Food Chem. 1992;40:1617-24.

21. Keeler RF, Baker DC, Gaffield W. Spirosolane-containing Solanum species and induction of congenital craniofacial malformations. Toxicon Off J Int Soc Toxinol. 1990:28:873.

22. Keeler RF, Young S, Brown D, Stallknecht GF, Douglas D. Congenital deformities produced in hamsters by potato sprouts. Teratology. 1978;17:327.

23. Gaffield W, Keeler RF. Induction of terata in hamsters by solanidane alkaloids derived from Solanum tuberosum. Chem Res Toxicol. 1996:9:426.

24. F W, YF Y, PZ L. A case-control study on the risk factors of neural tube defects in Shanxi province. Chin J Epidemiol. 2008;29:771-4.

25. Li Z, Ren A, Liu J, Pei L, Zhang L, Guo Z, Li Z. Maternal flu or fever, medication use, and neural tube defects: a population-based case-control study in northern China. Birth Defects Res A Clin Mol Teratol. 2007;79:295-300.

26. Millacura N, Pardo R, Cifuentes L, Suazo J. Effects of folic acid fortification on orofacial clefts prevalence: a meta-analysis. Public Health Nutr. 2017;20: 2260-8.

27. Berry RJ, Li Z, Erickson JD, Li S, Moore CA, Wang H, Mulinare J, Zhao P, Wong LY, Gindler J, et al. Prevention of neural-tube defects with folic acid in China. China-U.S. collaborative project for neural tube defect prevention. N Engl J Med. 1999;341:1485-90.

28. Hossain MB, Rawson A, Aguilo-Aguayo I, Brunton NP, Rai DK. Recovery of steroidal alkaloids from potato peels using pressurized liquid extraction. Molecules. 2015:20:8560-73.

29. Liu Chunhua LC, Guihao Y. Research Progress of Solanine in the potato and its product. J Anhui Agric Sci. 2010:38:3519-20.

30. Sizer CE, Maga JA, Craven CJ. Total glycoalkaloids in potatoes and potato chips. J Agric Food Chem. 1980;28:578-9.

31. Bushway RJ, Ponnampalam R. alpha.-Chaconine and .alpha.-solanine content of potato products and their stability during several modes of cooking. J Agric Food Chem. 1981;29:814-7. 
32. Blankemeyer JT, Atherton R, Friedman M. Effect of Potato Glycoalkaloids .Alpha.-Chaconine and .Alpha.-Solanine on sodium active transport in frog skin. J Agric Food Chem. 1995;43:636-9.

33. Blankemeyer JT, Stringer BK, Rayburn JR, Bantle JA, Friedman M. Effect of potato glycoalkaloids, alpha-chaconine and alpha-solanine, on membrane potential of frog embryos. J Agric Food Chem. 1992;40:2022-5.

34. Michalska L, Nagel G, Swiniarski E, Żydowo MM. The effect of a-solanine on the active calcium transport in rat intestine. Gen Pharmacol. 1985;16:69-70.

35. Toyoda M, Rausch WD, Inoue K, Ohno Y, Fujiyama Y, Takagi K, Saito Y.

Comparison of solanaceous glycoalkaloids-evoked $\mathrm{ca}(2+)$ influx in different types of cultured cells. Toxicol In Vitro. 1991;5:347-51.

Ready to submit your research? Choose BMC and benefit from:

- fast, convenient online submission

- thorough peer review by experienced researchers in your field

- rapid publication on acceptance

- support for research data, including large and complex data types

- gold Open Access which fosters wider collaboration and increased citations

- maximum visibility for your research: over $100 \mathrm{M}$ website views per year

At BMC, research is always in progress.

Learn more biomedcentral.com/submissions 